\title{
Strength of precast concrete shear joints reinforced with high-strength wire ropes
}

\author{
Joergensen, Henrik B.; Hoang, Linh Cao; Hagsten, Lars German
}

Published in:

Institution of Civil Engineers. Proceedings. Structures and Buildings

Link to article, DOI:

10.1680/jstbu.16.00096

Publication date:

2017

Document Version

Publisher's PDF, also known as Version of record

Link back to DTU Orbit

Citation (APA):

Joergensen, H. B., Hoang, L. C., \& Hagsten, L. G. (2017). Strength of precast concrete shear joints reinforced with high-strength wire ropes. Institution of Civil Engineers. Proceedings. Structures and Buildings, 170(3), 168179. https://doi.org/10.1680/jstbu.16.00096

\section{General rights}

Copyright and moral rights for the publications made accessible in the public portal are retained by the authors and/or other copyright owners and it is a condition of accessing publications that users recognise and abide by the legal requirements associated with these rights.

- Users may download and print one copy of any publication from the public portal for the purpose of private study or research.

- You may not further distribute the material or use it for any profit-making activity or commercial gain

- You may freely distribute the URL identifying the publication in the public portal 


\section{Strength of precast concrete shear joints reinforced with high-strength wire ropes}

1 Henrik B. Joergensen MSc, PhD

Assistant Professor, Department of Technology and Innovation, University of Southern Denmark, Odense, Denmark (corresponding author: hebj@iti.sdu.dk)

2 Linh C. Hoang MSc, PhD

Professor, Department of Civil Engineering, Technical University of Denmark, Lyngby, Denmark
3 Lars G. Hagsten MSc, PhD Professor, Aarhus University School of Engineering, Aarhus University, Aarhus, Denmark
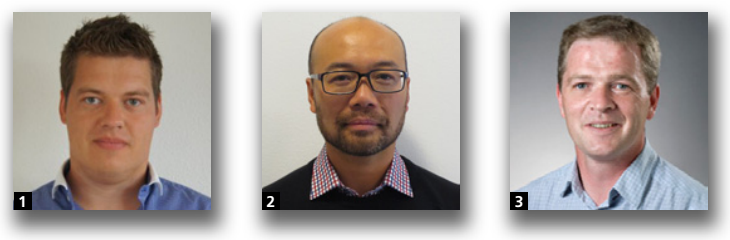

This paper concerns the in-plane shear strength of connections between precast concrete wall elements reinforced with looped high-strength wire ropes. The looped wire ropes are pre-installed in so-called 'wire boxes' which function as shear keys. Although only a small amount of research on the shear strength of such connections can be found in the literature, this type of connection is increasingly being used because wire ropes are much more constructionfriendly than traditional U-bars. A rigid plastic upper bound model for the shear strength of wall connections reinforced with looped wire ropes that are pre-installed in wire boxes is presented along with test results on the shear strength of connections with double-wire boxes. It is shown that the plastic solution agrees well with both the obtained test results and results from previously conducted tests.

\section{Notation}

$A_{\text {box }}$

$A_{\mathrm{c}}$

$A_{\mathrm{d}}$

$A_{\mathrm{sL}}$

$A_{\text {sw }}$

$a$

$a_{0, \mathrm{a}}, a_{0, \mathrm{~b}}$

$b$

$b_{\text {box }}$

$D$

$F_{\text {wire }}$

$F_{\text {wire,u }}$

$F_{\text {wire,0 }}$

$f_{\mathrm{c}}$

$f_{\text {cc }}$

$f_{\text {uw }}$

$f_{\mathrm{yL}}$

$k$

$L_{\text {box }}$ opening area of a wire box ( $\left.=b_{\text {box }} L_{\mathrm{box}}\right)$

cross-sectional area of circular core with diameter $D$ area of diagonal yield line cross-sectional area of lock bar cross-sectional area of looped wire rope

free distance between wire boxes

distance from end of connection to nearest box width of connection

opening width of connection; some wire boxes have sides that are bent in - here, the width is the opening width (i.e. without the sides)

\section{inner loop diameter of wire ropes} failure in the joint mortar

rupture strength of looped wire rope

$F_{\text {wire }}$ calculated without confinement from lock bars (i.e. $\sigma_{\mathrm{con}}=0$ )

uniaxial compressive strength of concrete/mortar apparent uniaxial compressive strength in triaxial stress state

ultimate strength of wire ropes

yield stress of lock bar

parameter related to the frictional angle of a

Coulomb material

length of wire box in the direction of the

connection/load $l_{\mathrm{a}} \quad$ distance from the end of the lock bar to the position of a diagonal yield line or a pair of overlapping wire ropes

$l_{\mathrm{b}} \quad$ basis anchorage length of reinforcement bars

$n_{\text {box }} \quad$ number of wire boxes in each joint surface

$n_{\text {cycle }} \quad$ number of unloads and reloads for cyclic tested connections

$n_{\text {wire }} \quad$ number of looped wire ropes in each box

$P_{\mathrm{u}, \mathrm{cal}} \quad$ calculated shear capacity

$P_{\mathrm{u}, \mathrm{test}} \quad$ tested shear capacity (i.e. ultimate test load)

$P_{\mathrm{u}, \mathrm{O}} \quad$ calculated shear capacity for a mechanism without diagonal yield line

$P_{\mathrm{u}, 1} \quad$ calculated shear capacity for a mechanism with diagonal yield lines (over one box)

$R_{\mathrm{y}, \mathrm{L}} \quad$ reduction factor of lacer bar contribution due to lack of anchorage

depth (thickness) of the connection

$\boldsymbol{u}_{i}, \boldsymbol{u}_{i}^{*} \quad$ displacement vector in yield line number $i$

$u_{t}, u_{l} \quad$ displacement in the $t$ - and $l$-direction, respectively

$\alpha \quad$ angle between failure surface and the

displacement vector

$\alpha_{i} \quad$ angle between failure surface and displacement vector number $i$

effectiveness factor for compressive strength of mortar

$\sigma_{\mathrm{c}} \quad$ plane hydrostatic compressive stress in the circular core 


\section{Offprint provided courtesy of www.icevirtuallibrary.com Author copy for personal use, not for distribution}

\begin{tabular}{|c|c|}
\hline$\sigma_{\mathrm{con}}$ & confinement stress provided by the lock bar \\
\hline$\tau_{\mathrm{c}}$ & $\begin{array}{l}\text { shear stress in mortar between overlapping } \\
\text { wire loops }\end{array}$ \\
\hline$\Phi_{\mathrm{L}}$ & mechanical ratio of lock bar \\
\hline$\Phi_{\mathrm{T}}$ & $\begin{array}{l}\text { mechanical ratio of transverse reinforcement } \\
\text { (wire ropes) }\end{array}$ \\
\hline$\Phi_{\mathrm{T}, 0}$ & $\begin{array}{l}\text { mechanical ratio of transverse reinforcement with } \\
\text { zero confinement contribution }\end{array}$ \\
\hline$\varphi$ & angle of friction for modified Coulomb materials \\
\hline$\phi_{\mathrm{L}}$ & diameter of lock bar \\
\hline$\phi_{\mathrm{w}}$ & diameter of looped wire rope \\
\hline
\end{tabular}

\section{Introduction}

This paper deals with the in-plane shear capacity of vertical wire loop connections between precast concrete wall elements. Traditionally, connections between precast wall elements are made as keyed joints transversely reinforced with overlapping U-bars. The overlapping U-bars are normally placed pairwise with contact and form a cylindrical core, which confines a socalled lock bar. In building structures, such connections are usually grouted with mortar. In practice, the assembly sequence of the precast elements may require that a number of wall elements have to be installed (i.e. put in place) as a vertical 'drop down'. This installation manoeuvre is only possible if the overlapping U-bars are bent up prior to installation. When the U-bars are of diameter larger than about 10-12 mm, bend-up and manual straightening of the U-bars after installation is not a practical option. In this context, the so-called wire loop connection (see e.g. Bachmann and Steinle, 2011; Kintscher, 2007) is a more construction-friendly solution. In wire loop connections, the U-bars are replaced by looped wire ropes. The wire ropes have the advantage of being flexible (they have virtually no bending stiffness), which makes vertical installation of the precast elements much easier. The wire loops are usually pre-installed in aluminium/steel boxes called wire boxes. The boxes contain either one or two pre-installed looped wire ropes (i.e. $n_{\text {wire }}=1$ or 2), as illustrated in Figure 1 .

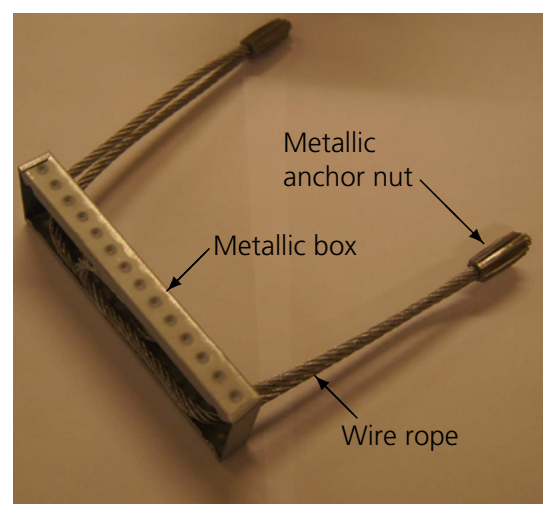

(a)
Figure 2 shows an example of how wire boxes are placed in a connection between two wall elements. The wire boxes have their opening facing the connection. Hence, when filled with mortar, the boxes will serve as shear keys.

The wire ropes currently available in the construction industry have a very brittle tensile failure mode without any yield plateau in the stress-strain relationship (Joergensen, 2014). As such, the wire ropes do not fulfil the code requirements for ductility (e.g. Eurocode 2 (Danish Standards, 2005)). To overcome the problem of brittle failure and to allow redistributions of stress, loop connections must be designed in such a way that the wire ropes become the 'strongest link' in the connection. The load-carrying capacity will in this way be governed by yielding of the lock bar in combination with crushing of the joint mortar. This design approach will ensure a warning of failure, especially if the mortar is confined.

A model for how to prevent premature failure of the wire ropes is presented in this paper. On the basis of this model, upper bound rigid plastic solutions are then derived for prediction of the shear capacity of wire loop connections. The solutions are compared with test results and it is shown that good agreement is obtained when an existing formula for the effective compressive strength of concrete is adjusted to cover the use of mortar.

In Denmark, a few test series, primarily with single-wire boxes, have been conducted over the last 10-15 years (Andersen and Poulsen, 2002; Frederiksen and Madsen, 2011). However, the number of test results available to the public is still very limited, especially for tests with double-wire boxes. Therefore, in addition to the theoretical models, this paper also presents 11 new tests on the shear strength of loop connections with double-wire boxes. To the best knowledge of the authors, such tests have not previously been reported in the international literature. For an overview, a summary of the tests from previous investigations is also given in this paper.

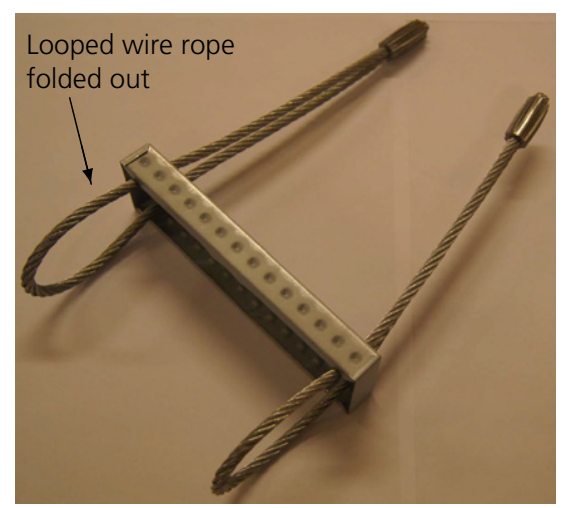

(b)

Figure 1. Double-wire box before (a) and after (b) the wires are folded out 


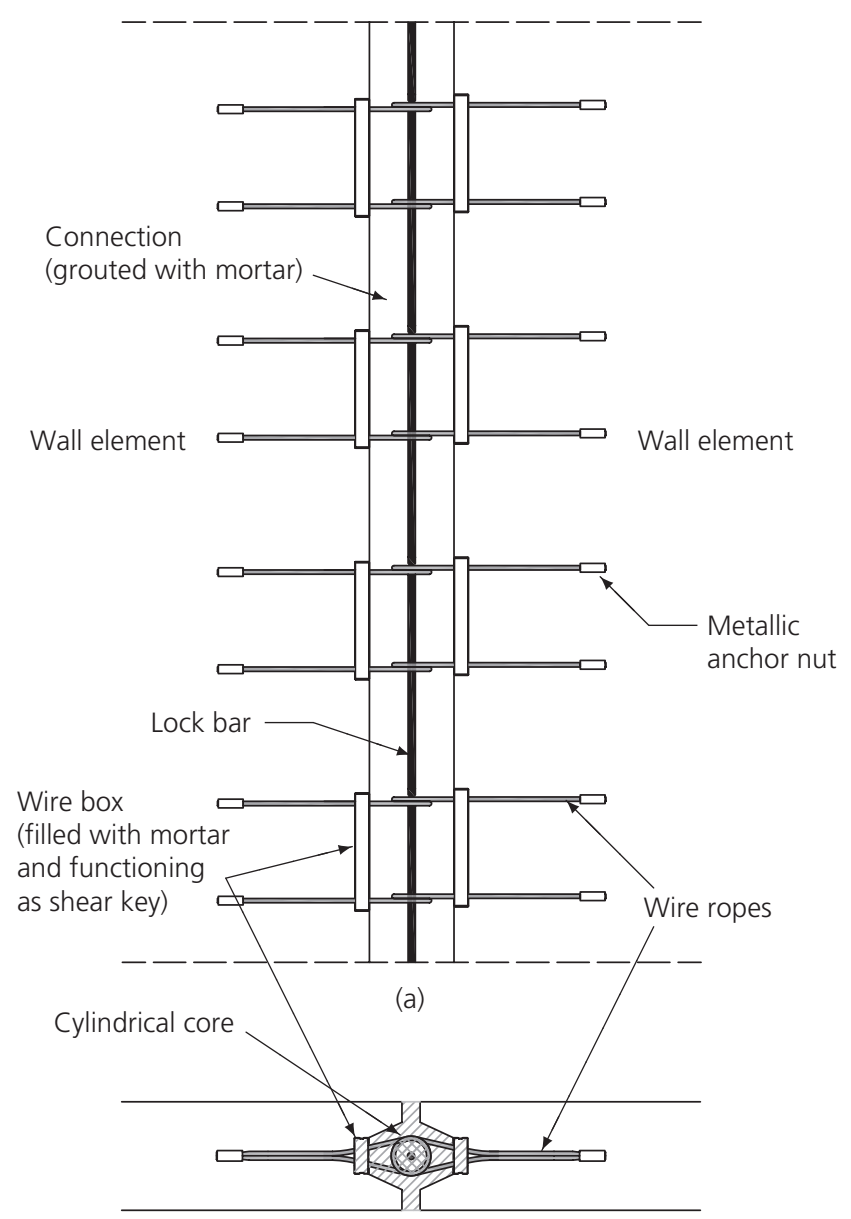

(b)

Figure 2. Wire loop connection between two wall elements: (a) plane view; (b) cross-sectional view

\section{Analytical solutions}

A rigid plastic upper bound model for calculation of the shear strength of wire loop connections is presented in this section. The failure mechanisms considered are idealisations and simplifications of failures observed in tests.

The lack of ductility in the wire ropes means that plasticity modelling should not be carried out unless the wire ropes are the 'strongest link' in the connections. In other words, the capacity of the connection has to be governed by failure in the mortar or yielding of the lock bar, or both. This mode of failure is therefore assumed and required in the following. The modelling is therefore initiated by setting up the requirements for the wire ropes being the 'strongest link'. The force of the wire ropes serves as input to the later calculation of the internal work/dissipation.

\subsection{Tensile capacity of overlapping wire ropes}

To transfer shear across the connection, the wire ropes have to be stressed to tension. Therefore, as a first step towards calculation of the shear strength of the connections, the tensile capacity of the overlapping wire loops needs to be calculated.

The wire ropes used in shear connections typically have a high tensile strength (larger than $1000 \mathrm{MPa}$ ) and a relatively small nominal cross-sectional diameter, $\phi_{\mathrm{w}}$ (typically $6 \mathrm{~mm}$ ). The ropes are bent in a loop that typically has a diameter, $D$, of the order of 38-65 mm. The combination of these characteristics results, in practice, in very high concentrated stresses in the parts of the joint mortar that are confined by the overlapping wire loops. The tension force that can be transferred between the overlapping loops may therefore be limited by local crushing of the joint mortar. One may imagine that the wire loops cut through the mortar. Such a failure mode is by no means simple to model. In the following, the tensile capacity of overlapping wire loops is therefore modelled in an approximate manner by assuming simplified stress states.

Figure 3 shows an idealisation of two overlapping wire loops that transfer the tension force $F_{\text {wire }}$. The overlapping wire loops are assumed to form a circular core with diameter corresponding to the loop diameter $D$. Since $\phi_{\mathrm{w}}$ is significantly smaller than $D$, it may, as a start, be assumed that the loops confine a plane circular disc of mortar of diameter $D$ and thickness $\phi_{\mathrm{w}}$.

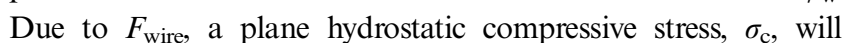
develop in the disc. The following relation may be established.

1. $\sigma_{\mathrm{c}} \cong \frac{F_{\text {wire }}}{D \phi_{\mathrm{w}}}$

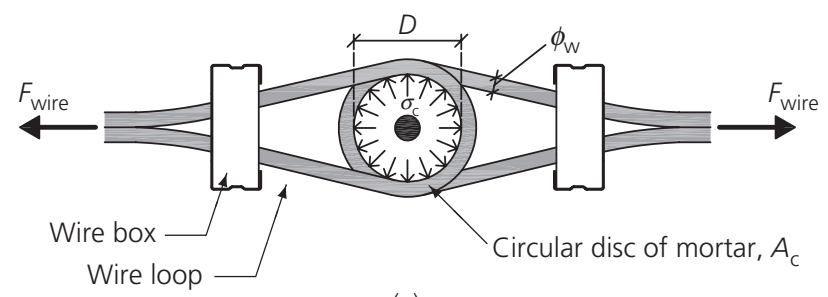

(a)

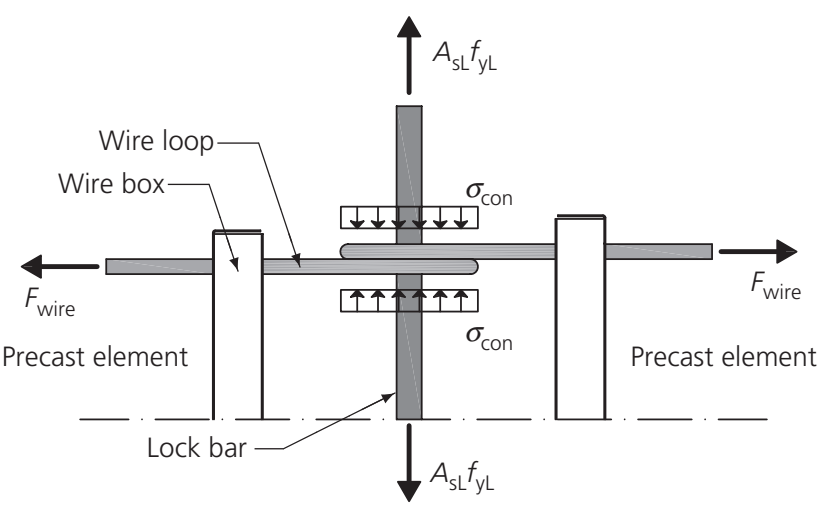

(b)

Figure 3. Idealised stress state in circular disc of mortar within the overlap of two wire loops: (a) top view; (b) side view 
In the direction of the lock bar (i.e. perpendicular to the plane of the circular disc of mortar), a confinement stress, $\sigma_{\mathrm{con}}<\sigma_{\mathrm{c}}$, is assumed to develop (see Figure 3). The confinement stress is provided by the lock bar and can, on the basis of lower bound plasticity reasoning, be determined as

2. $\sigma_{\mathrm{con}}=\frac{A_{\mathrm{sL}} f_{\mathrm{yL}}}{A_{\mathrm{c}}}$

where $A_{\mathrm{sL}}$ and $f_{\mathrm{yL}}$ are, respectively, the cross-sectional area and the yield stress of the lock bar while $A_{\mathrm{c}}=0.25 \pi D^{2}$ is the area of the disc.

Strictly speaking, the above approximation of a circular disc of thickness $\phi_{\mathrm{w}}$ requires that the two wire loops are placed at exactly the same level. This, of course, is not possible. An additional stress condition must therefore be considered. Since the wire loops are placed at different levels (but assumed to be in contact), shear stresses will have to develop in order to transfer $F_{\text {wire. }}$ This is illustrated in Figure 4. From equilibrium requirements, the shear stress, $\tau_{\mathrm{c}}$, can be determined as

3. $\tau_{\mathrm{c}}=\frac{F_{\text {wire }}}{A_{\mathrm{c}}}$

where $A_{\mathrm{c}}$, as already noted, is the area of the confined disc.

To establish strength criteria for $\sigma_{\mathrm{c}}$ and $\tau_{\mathrm{c}}$, a failure criterion for mortar in triaxial stress state is required. According to Nielsen and Hoang (2011), confined mortar behaves somewhat between the behaviour of concrete and cement paste. Therefore, in the following, a combination of the failure criterion for concrete and the failure criterion for cement paste is adopted for confined mortar. The idea here is to take the lower envelop curve of the two basis criteria, which should provide a lower bound for the failure criterion for mortar.

The modified Coulomb failure criterion usually adopted for concrete stressed in compression may be written as

4. $\sigma_{\mathrm{c}}=f_{\mathrm{c}}+k \sigma_{\mathrm{con}}$

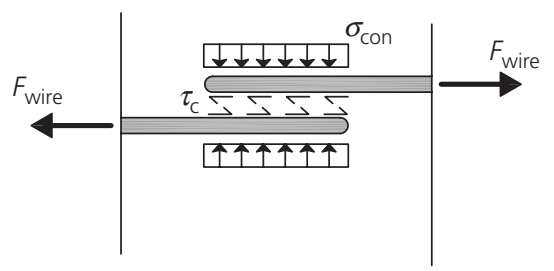

Figure 4. Transfer of shear stress $\tau_{c}$ between overlapping wire loops where $k$ is equal to

5. $k=\frac{1+\sin \varphi}{1-\sin \varphi}$

For normal-strength concrete, the internal angle of friction may be taken as $\varphi=\arctan (3 / 4)$, meaning that $k=4$.

According to tests reported by Dahl (1992) and Hansen (1994), cement paste under triaxial stress conditions with high confinement behaves like a material with frictional angle $\varphi=0$ (i.e. no dilatation takes place at failure and $k=1$ ). Based on these tests, the failure criterion for highly confined cement paste may be written as (see also Nielsen and Hoang, 2011)

$$
\text { 6. } \sigma_{\mathrm{c}}=f_{\mathrm{cc}}+k \sigma_{\mathrm{con}} \quad(k=1 \text { for cement paste with } \varphi=0)
$$

Here, $f_{\text {cc }}$ is called the apparent uniaxial compressive strength of confined cement, which is greater than the true uniaxial strength $f_{\mathrm{c}}$. The relationship between $f_{\mathrm{cc}}$ and $f_{\mathrm{c}}$ for cement paste can be obtained from tests. Based on the tests reported by Nielsen and Hoang (2011), the relationship can be simplified as follows.

7. $\frac{f_{\mathrm{cc}}}{f_{\mathrm{c}}} \begin{cases}\frac{1.5-1.32}{40-20}\left(f_{\mathrm{c}}-20\right)+1.32 & \text { for } 20 \mathrm{MPa} \leq f_{\mathrm{c}}<40 \mathrm{MPa} \\ \frac{1.65-1.5}{70-40}\left(f_{\mathrm{c}}-40\right)+1.5 & \text { for } 40 \mathrm{MPa} \leq f_{\mathrm{c}}<70 \mathrm{MPa} \\ \frac{1.75-1.65}{100-70}\left(f_{\mathrm{c}}-70\right)+1.65 & \text { for } 70 \mathrm{MPa} \leq f_{\mathrm{c}}<100 \mathrm{MPa}\end{cases}$

By combining criteria Equations 4 and 6, the following lower envelop curve is obtained for calculation of the compressive stress that can be resisted by the disc of mortar confined by the overlapping wire loops.

8. $\sigma_{\mathrm{c}}=\min \left\{\begin{array}{l}f_{\mathrm{c}}+4 \sigma_{\mathrm{con}} \\ f_{\mathrm{cc}}+\sigma_{\mathrm{con}}\end{array}\right.$

This criterion may be transformed into a $(\sigma, \tau)$ stress space. In doing so, the following condition is obtained.

9. $\tau=\min \left\{\begin{array}{l}\frac{1}{4} f_{\mathrm{c}}+\frac{3}{4} \sigma_{\mathrm{con}} \\ \frac{1}{2} f_{\mathrm{cc}}\end{array}\right.$

Now, with the strength and stresses defined, the tensile capacity of overlapping wire loops, $F_{\text {wire, }}$ may be determined by combining Equations 1 and 2 with Equation 8 and 
Equation 3 with Equation 9. The result is

10. $F_{\text {wire }}=\min \left\{\begin{array}{l}\left(f_{\mathrm{c}}+4 \sigma_{\mathrm{con}}\right) D \phi_{\mathrm{w}} \\ \left(f_{\mathrm{cc}}+\sigma_{\mathrm{con}}\right) D \phi_{\mathrm{w}} \\ \left(\frac{1}{4} f_{\mathrm{c}}+\frac{3}{4} \sigma_{\mathrm{con}}\right) A_{\mathrm{c}} \\ \frac{1}{2} f_{\mathrm{cc}} A_{\mathrm{c}}\end{array}\right.$

As mentioned, plastic modelling should not be carried out if rupture of the wire ropes is decisive. For this reason, the following requirement must be fulfilled.

11. $F_{\text {wire }}<F_{\text {wire, } \mathrm{u}} \sim f_{\text {uw }} A_{\text {sw }}$

Here, $F_{\text {wire, }}$ is the rupture strength of a wire loop ( $f_{\mathrm{uw}}$ and $A_{\mathrm{sw}}$ being the tensile strength and the cross-sectional area of the wire ropes, respectively). The condition stated in Equation 11 leads to requirements for the mortar strength. As shown by Joergensen (2014), for typical values of $D, \phi_{\mathrm{w}}, A_{\mathrm{sL}}$ and $f_{\mathrm{yL}}$, rupture of wire ropes can be avoided if the joint mortar has a uniaxial compressive strength less than approximately $60 \mathrm{MPa}$. Above this limit, the failure mode depends on the specific layout of the wire ropes in the connection.

On the basis of Equation 10, it is now possible to estimate the plastic energy that is dissipated when the overlapping wire loops are tensioned to $F_{\text {wire. }}$. How this is done will be described in the next subsection.

It should be noted that the stress state in Figures 3 and 4 can only develop when the overlapping wire ropes comes from two opposing wire boxes. Thus, the developed solution in this paper can only be used for wall elements that are placed in the same plane.

\subsection{Shear failure mechanism analysis}

A number of push-off tests to study the shear strength of wire loop connections have previously been carried out (Andersen and Poulsen, 2002; Frederiksen and Madsen, 2011). These tests show two typical failure modes when the joint mortar is governing. In the following, these experimental observations are used as inspiration to develop and analyse two idealised shear failure mechanisms. The failure mechanisms lead to solutions according to the upper bound theorem of plastic theory. The shear capacity is therefore taken as the minimum of the two solutions.

\subsubsection{Mechanism without diagonal yield lines}

The first type of mechanism involves only yield lines formed in the shear load direction. Figure 5(a) shows the failure as observed in tests carried out by Frederiksen and Madsen

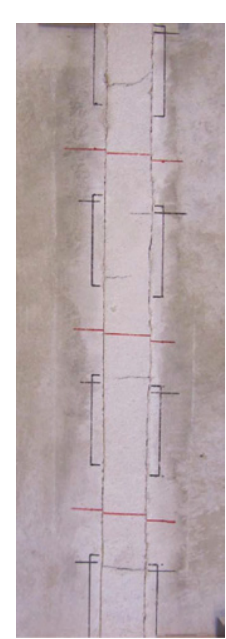

(a)

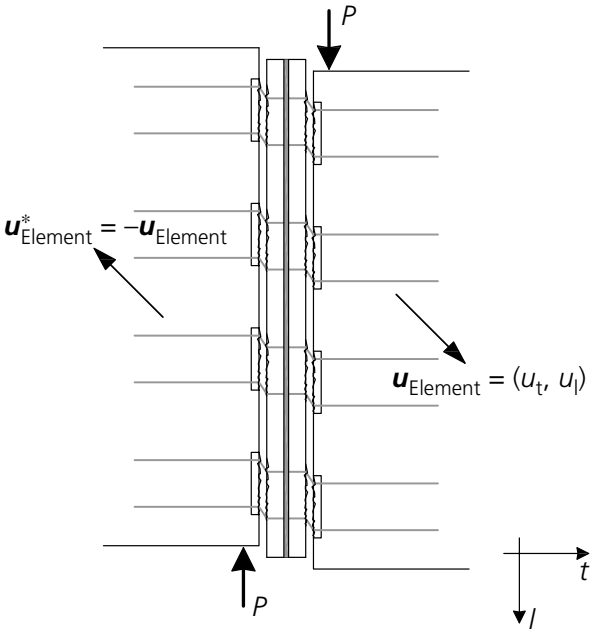

(b)
Figure 5. Failure mechanism without diagonal yield lines: (a) failure observed in tests conducted by Frederiksen and Madsen (2011); (b) idealised failure mechanism

(2011); the original positions of the wire boxes are drawn on the surface of the specimen. It appears from Figure 5(a) that the relative displacement in the joint surfaces is practically the same over the entire length of the connection. This is indicated by the lines across the connections, which were drawn as continuous straight lines prior to testing. Based on this observation, the idealised failure mechanism shown in Figure 5(b) is considered. The mechanism, which is similar to that developed by Jensen (1976) for keyed shear joints, consists of vertical yield lines developed along the two joint surfaces. At the position of the wire boxes - which are filled with mortar - the yield lines have to cut through the mortar. Therefore, at these locations, plastic energy will be dissipated. The interface between the joint mortar and the precast elements is normally considered smooth. Any resistance against failure at the smooth interfaces is neglected (in the tests considered in this paper, the interfaces were greased before casting of the joint mortar). As shown in Figure 5(b), the precast elements are assumed to move away from the connection by displacements $\left(u_{t}, u_{l}\right)$ and $\left(-u_{t},-u_{l}\right)$, respectively. The rate of displacement, $u_{t} / u_{l}$, dictates the amount of plastic energy to be dissipated in the yield lines crossing the opening area of the wire boxes. Detailed calculations of the dissipated energy are given by Joergensen (2014). The calculations are based on the so-called dissipation formulas, which can be found in the work of Nielsen and Hoang (2011). The dissipation per unit area of a yield line in concrete can be calculated from the following equation.

12. $W_{\mathrm{A}}=\frac{1}{2} v f_{\mathrm{c}}(1-\sin \alpha)|\boldsymbol{u}|$ 


\section{Offprint provided courtesy of www.icevirtuallibrary.com Author copy for personal use, not for distribution}

Besides the plastic energy dissipated in the yield lines, there is also a contribution from the overlapping wire loops. This is so because the precast elements have a transverse component, $u_{t}$, which means that the tensile capacity of the overlapping wire loops has to be mobilised. Hence, whenever a vertical yield line crosses a wire loop, the wire loop will contribute with an internal work amounting to $F_{\text {wire }} \cdot u_{t}$. Thereby, the total dissipated energy in the connection can be calculated from

$$
\text { 13. } W_{\mathrm{I}}=\underbrace{2 \frac{1}{2} v f_{\mathrm{c}} n_{\text {box }} A_{\text {box }}(1-\sin \alpha)|\boldsymbol{u}|}_{\text {mortar contribution }}+\underbrace{2 F_{\text {wire }} n_{\text {box }} n_{\text {wire }} u_{t}}_{\text {wire contribution }}
$$

The factor $v$ denotes the effectiveness factor, which will be further discussed in Section 2.3. $A_{\text {box }}$ denotes the opening area of each wire box and $n_{\text {box }}$ is the number of wire boxes placed in one joint interface.

By equating the total dissipated energy with the external work (in this case given as $W_{\mathrm{E}}=2 P u_{l}$ ), an upper bound for the shear capacity of the connection may be found. This upper bound may then be minimised with respect to the rate of displacement $u_{t} / u_{l}$, while keeping account of the normality condition of plastic theory. In doing so, an optimal solution is obtained. The solution reads (see Joergensen (2014) for further explanation)

14. $P_{\mathrm{u}, 0}=v f_{\mathrm{c}} n_{\mathrm{box}} A_{\mathrm{box}} \begin{cases}\sqrt{\frac{\Phi_{\mathrm{T}}}{v}\left(1-\frac{\Phi_{\mathrm{T}}}{v}\right)} & \text { for } \frac{\Phi_{\mathrm{T}}}{v}<\frac{1}{5} \\ \frac{1}{4}+\frac{3}{4} \frac{\Phi_{\mathrm{T}}}{v} & \text { for } \frac{\Phi_{\mathrm{T}}}{v} \geq \frac{1}{5}\end{cases}$

Here the subscript $\mathrm{u}, 0$ indicates that the solution is related to a mechanism without diagonal yield lines. $\Phi_{\mathrm{T}}$ is the mechanical ratio of transverse reinforcement (the wire loops) and is given by

$$
\text { 15. } \Phi_{\mathrm{T}}=\frac{n_{\text {wire }} F_{\text {wire }}}{f_{\mathrm{c}} A_{\text {box }}}
$$

where $n_{\text {wire }}$ denotes the number of wire loops pre-installed in each box $\left(n_{\text {wire }}=1\right.$ or 2$)$.

\subsubsection{Mechanism with diagonal yield lines}

The second type of mechanism involves vertical as well as diagonal yield lines. Figure 6(a) shows an example of this mechanism, as observed in some tests by Frederiksen and Madsen (2011). It can be seen from the lines drawn prior to testing that the relative displacement between the connection and the precast elements varies in the load direction. At the top, there is practically no relative displacement between the connection and the precast element on the left-hand side,

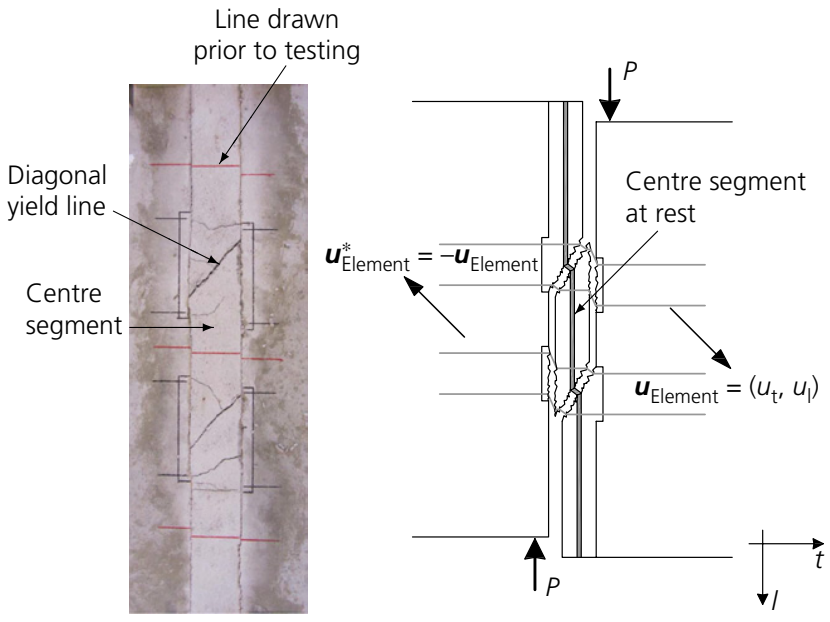

(a)

(b)

Figure 6. Failure mechanism with diagonal yield lines: (a) failure observed in tests of Frederiksen and Madsen (2011); (b) idealised failure mechanism

whereas a large relative displacement is observed for the precast element to the right. At the bottom of the connection, the opposite scenario is observed. Finally, at the middle of the connection, the left-hand and the right-hand precast elements have a relative displacement that is about half of the displacement at the top and at the bottom. This observed failure was idealised and simplified as shown in Figure 6(b). Here, the system of vertical and diagonal yield lines divide the connection into a number of segments (three in the case shown). The centre segment has the shape of a parallelogram. The top segment of the connection is attached to the precast element on the left-hand side and the bottom segment of the connection is attached to the precast element on the right-hand side. When more than two boxes are placed in each precast element, the number of parallelogram-shaped segments increases. As an example, Figure 7 shows the system of yield lines in a connection with four boxes in each precast element.

Similar to the case treated in Section 2.2.1, the rigid body displacements of the two precast elements are here described by the vectors $\left(u_{t}, u_{l}\right)$ and $\left(-u_{t},-u_{l}\right)$, respectively. To obtain a variation in the relative displacements as observed in Figure 6(a), the segments of mortar have to undergo rigid body displacement as well. With reference to Figure 7, the centre segment is here assumed to be at rest while the two neighbouring segments are displaced by the vectors $\boldsymbol{u}_{4}=\left(0,2 / 4 u_{l}\right)$ and $\boldsymbol{u}_{4}{ }^{*}=\left(0,-2 / 4 u_{l}\right)$, respectively. The remaining two segments are attached to the precast elements and will therefore follow the same displacement as the respective precast element. From the described displacement field, it appears that the relative displacement in each of the diagonal yield lines is identical and amounts to $\left(0,1 / 2 u_{l}\right)$. This applies to the case shown in Figure 7, while for the general case with 


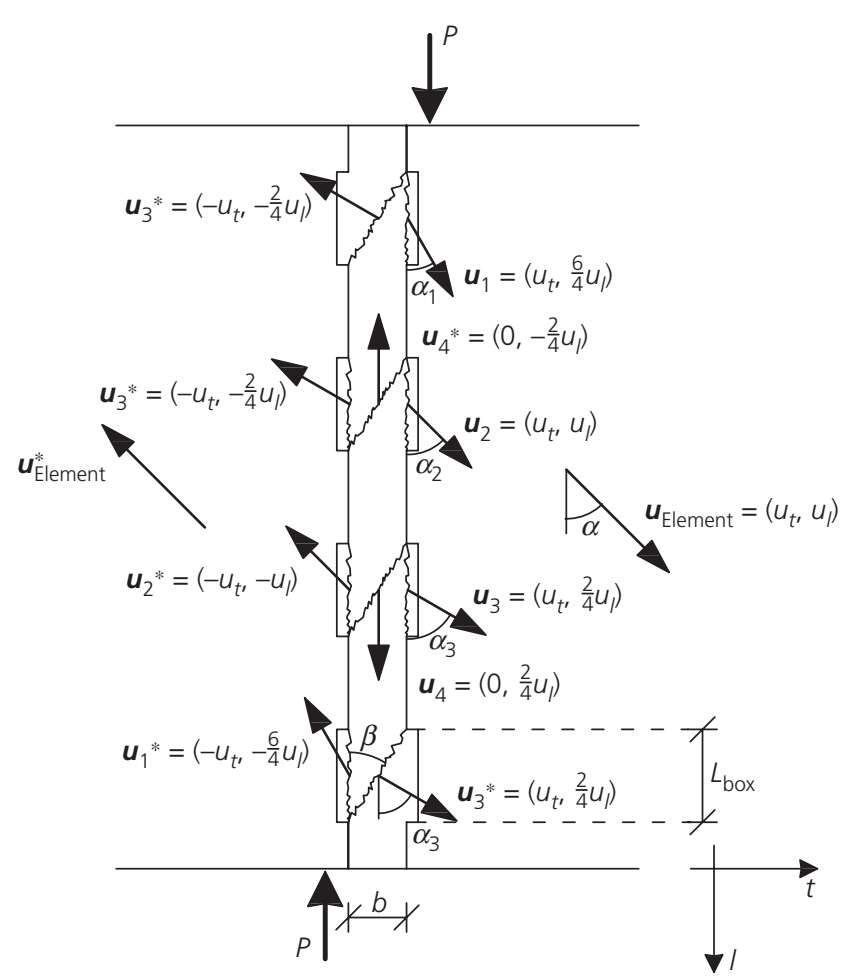

Figure 7. Failure mechanism with diagonal yield lines and relative displacement vectors in yield lines

$n_{\text {box }}$ number of wire boxes, the relative displacement may be shown to be $\left(0,2 u_{l}\right) / n_{\text {box }}$ (Joergensen, 2014). Finally, for each of the vertical yield lines, the relative displacement must be determined by subtracting the displacement vector of the adjacent segment of mortar from the displacement vector of the precast element. This results in different relative displacements internal work (which at each diagonal yield line will be equal to the yield force of the lock bar multiplied by $2 u_{l} / n_{\text {box }}$ ). Because the lock bar hereby is included directly, its yield capacity cannot once more be mobilised to develop confinement stresses in the circular core of mortar enclosed by the overlapping wire loops. This means that when the tensile capacity of the transverse reinforcement (the looped wire ropes) is determined, the confinement stress, $\sigma_{\text {con, must be }}$ taken as zero. The tensile capacity, given in Equation 10, is hereby reduced to

16. $F_{\text {wire }, 0}=\min \left\{\begin{array}{l}f_{\mathrm{c}} D \phi_{\mathrm{w}} \\ \frac{1}{4} f_{\mathrm{c}} A_{\mathrm{c}}\end{array}\right.$

Here, the subscript 0 indicates that the tensile capacity is calculated with zero confinement stress. Equation 16 is used when the contribution to the dissipated energy from the overlapping looped wire ropes has to be calculated. This contribution amounts to $F_{\text {wire }, 0} \cdot u_{t}$ whenever a vertical yield line crosses a wire loop. Now, by equating the total internal work with the external work, one arrives at an upper bound for the shear strength associated with the considered failure mechanism. To enable presentation of the solution in a dimensionless form, it is convenient to introduce the parameter $\Phi_{\mathrm{T}, 0}$

$$
\text { 17. } \Phi_{\mathrm{T}, 0}=\frac{n_{\mathrm{wire}} F_{\mathrm{wire}, 0}}{f_{\mathrm{c}} A_{\mathrm{box}}}
$$

The upper bound solution for a connection with $n_{\text {box }}$ number of wire boxes in each precast element may be shown to be (Joergensen, 2014)

$$
\frac{P_{\mathrm{u}, 1}}{v f_{\mathrm{c}} n_{\mathrm{box}} A_{\mathrm{box}}}=\frac{\tan \alpha}{n_{\mathrm{box}}} \sum_{i}^{n_{\mathrm{box}}-1} \frac{1 / 2}{\sin \left\{\arctan \left[n_{\mathrm{box}} / 2\left(n_{\mathrm{box}}-1\right)\right] \tan \alpha\right\}}
$$

18.

$$
\begin{aligned}
& +\tan \alpha\left[\frac{A_{\mathrm{d}} / n_{\mathrm{box}} A_{\mathrm{box}}}{2 \sin \left\{\arctan \left[\left(n_{\mathrm{box}} / 2\right) \tan \alpha\right]\right\}}+\frac{A_{\mathrm{box}}-t L_{\mathrm{box}}}{2 n_{\mathrm{box}} A_{\mathrm{box}}}+\left(\frac{\Phi_{\mathrm{T}, 0}}{v}-\frac{1}{2}\right)\right] \\
& +\left(\frac{\Phi_{\mathrm{L}}}{v}-\frac{1}{2}\right) \frac{b t}{n_{\mathrm{box}} A_{\mathrm{box}}}+\frac{n_{\mathrm{box}}-2}{2 n_{\mathrm{box}}} \frac{A_{\mathrm{d}}}{n_{\mathrm{box}} A_{\mathrm{box}}}
\end{aligned}
$$

depending on the position of the vertical yield lines. This is illustrated in Figure 7 by the vectors $\boldsymbol{u}_{1}, \boldsymbol{u}_{2}, \boldsymbol{u}_{3}, \boldsymbol{u}_{1}{ }^{*}, \boldsymbol{u}_{2}{ }^{*}$ and $\boldsymbol{u}_{3}{ }^{*}$. The length and direction of the vectors of relative displacement as described above are used to calculate the energy dissipated in the yield lines.

The diagonal yield lines are crossing the lock bar. Hence, in this mechanism, the lock bar has a direct contribution to the in which $b$ and $t$ respectively denote the width and depth of the connection, $L_{\text {box }}$ is the length of the wire box (in the shear load direction), $A_{\mathrm{d}}$ is the surface area of a diagonal yield line and $\Phi_{\mathrm{L}}$ defines the mechanical ratio of the lock bar.

19. $A_{\mathrm{d}}=t \sqrt{b^{2}+L_{\mathrm{box}}^{2}}$ 
20. $\Phi_{\mathrm{L}}=\frac{f_{\mathrm{yL}} A_{\mathrm{sL}}}{f_{\mathrm{c}} b t}$

The upper bound solution (Equation 18) is seen to be a function of the displacement rate, $\tan \alpha=u_{t} / u_{l}$. An optimal upper bound solution may therefore be found by minimisation with respect to $\tan \alpha$. Unlike the previous case, it is here not possible to determine an analytical optimal solution. The result has to be found numerically. In this context, it is important to take into account the normality condition of plastic theory. This may be shown to imply that $\tan \alpha$ must fulfil the following condition (see Joergensen, 2014)

21. $\tan \alpha=\frac{u_{t}}{u_{l}} \geq \frac{3}{2} \frac{n_{\mathrm{box}}-1}{n_{\text {box }}}$

\subsection{The effectiveness factor}

As is usual when applying the theory of plasticity to structural concrete, it is necessary to introduce the so-called effectiveness factor, $v$. This factor takes into account the softening and cracking behaviour of concrete/mortar as well as other phenomena not included in the simplified plastic solutions. The effectiveness factor can either be found by calibrating the theoretical solution with test results or adopted from a similar well-documented problem. In the present study, a combination of these two approaches is used. Since the shear problem considered here bears resemblance to beam shear problems, it is worthwhile investigating if the structure of a $v$ formula for shear in beams can be used. Zhang (1994) developed the socalled crack sliding model for calculating the shear strength of beams without shear reinforcement. The formula includes the dependency on the ratio of longitudinal reinforcement, which is mainly due to dowel action. However, dowel action cannot take place in a wire loop connection loaded in shear because the wire ropes are flexible. Additionally, the formula for the beam shear effectiveness factor takes into account the size effect by including the height of the yield line (in the load direction). In the case of a wire loop connection, the geometrical parameter that dictates the size of the yield lines in the direction of the shear load is $L_{\mathrm{box}}$. Based on these qualitative arguments, the applicability of Equation 22 is investigated, where $f_{\mathrm{c}}$ is in $\mathrm{MPa}$ and $L_{\mathrm{box}}$ is in $\mathrm{m}$.

22. $v=\frac{0 \cdot 75}{\sqrt{f_{\mathrm{c}}}}\left(1+\frac{1}{\sqrt{L_{\mathrm{box}}}}\right)$

Here, the factor 0.75 is a replacement for the factor of 0.88 in the original formula for shear in concrete beams. Since mortar has a smaller aggregate volume content than concrete and the maximum aggregate size in mortar is normally $2-4 \mathrm{~mm}$ or less, the effect of aggregate interlock can be expected to be less pronounced in diagonal yield lines formed in mortar than in concrete.

\section{Experimental results}

An experimental programme of 30 shear push-off tests was recently carried out with the third author as principal investigator (Hagsten, 2013). In the programme, 11 of the tested connections were designed with double-wire boxes (i.e. two wire loops pre-installed in each box in the connection). The other specimens were designed with either U-bars or with lightweight concrete, which is not relevant in this context. Therefore, in the following, the 11 tests with double-wire boxes are referred to as the experimental programme.

The tests were conducted as so-called push-off tests. A schematic illustration of the test setup is given in Figure 8. Such a push-off type of test ensures pure shear in the centre plan of the connection and has also been used for the testing of shear connections reinforced with U-bars (see e.g. Hansen et al., 1976; Mattock and Hawkins, 1972).

Casting of the test specimens was conducted in two phases. First, the precast concrete elements, representing wall elements, were cast. Subsequently, the connections were cast with mortar having a mean compressive strength of $f_{\mathrm{c}}=24.8 \mathrm{MPa}$ and a maximum aggregate size of $2 \mathrm{~mm}$. The aim of the experimental programme was to test the shear capacity of connections where the joint mortar was governing for strength. The presented model for the prevention of premature failure of wire ropes was therefore used to design the connections. Furthermore, to ensure failure in the joint, a stronger concrete $\left(f_{\mathrm{c}}=48.1 \mathrm{MPa}\right)$ was used in the precast elements, which were also heavily reinforced to obtain over strength.

Figure 9 shows the general layout of the specimens and Table 1 lists the geometrical and mechanical parameters of each specimen. The experimental programme was divided into four series of tests with two or three geometrically identical specimens. The first specimen in each series was tested in monotonic displacement-controlled loading. The remaining specimens in each series were subjected to cyclic loading and unloading with a peak load of $60 \%$ of the expected ultimate capacity (based on the strength of the first test in each series). The number of load cycles $\left(n_{\text {cycle }}\right)$ was either 3 or 50 before the load finally was increased monotonically up to specimen failure. It appears, however, that the cyclic loading/unloading did not result in any consistent difference in the ultimate capacity. Cyclic loading was mainly performed to study the behaviour of the connections at load levels corresponding to the serviceability limit state; this issue is not treated in this paper.

\section{Comparison of model with test results}

The upper bound shear capacity models presented in this paper were compared with results from recently performed tests (Table 1) as well as test results from two previous 


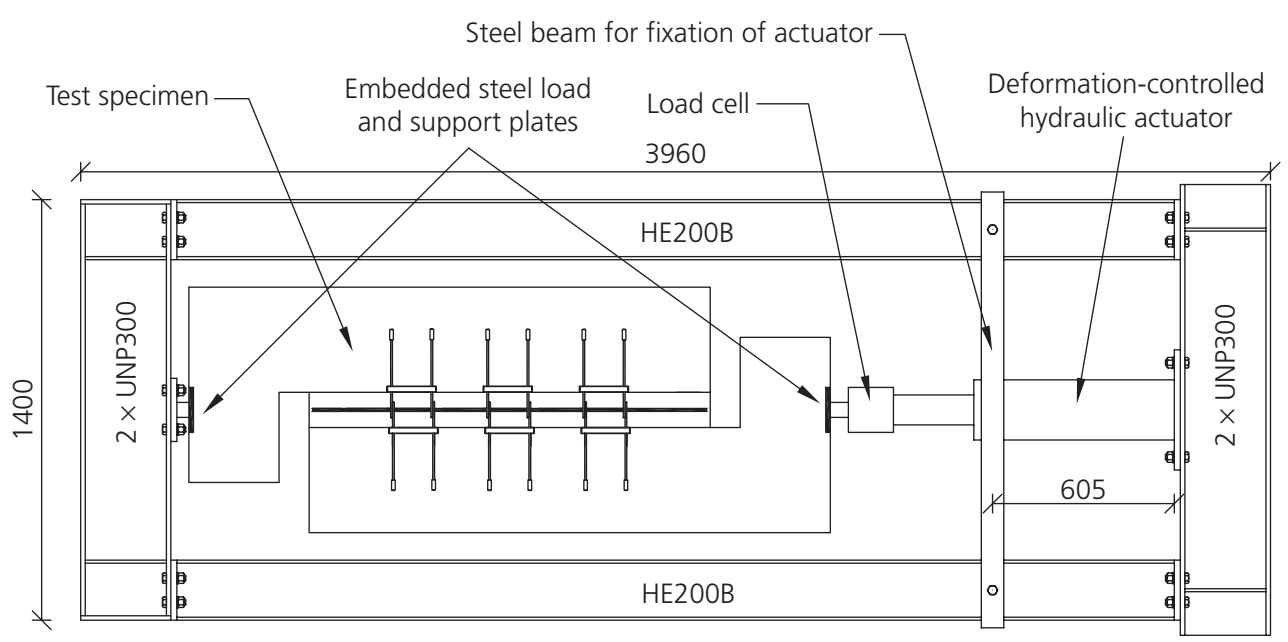

Figure 8. Test setup (dimensions in $\mathrm{mm}$ )

investigations (Andersen and Poulsen, 2002; Frederiksen and Madsen, 2011). The results of the latter two series are summarised in Table 2 and a more detailed description can found in the work of Joergensen (2014).

For all tested connections the connection thickness was $t=150 \mathrm{~mm}$. Furthermore, the wire ropes in all tests (including the specimens described in Section 3) had the same (standard) nominal diameter of $\phi_{\mathrm{w}}=6$. The strength of a single wire rope

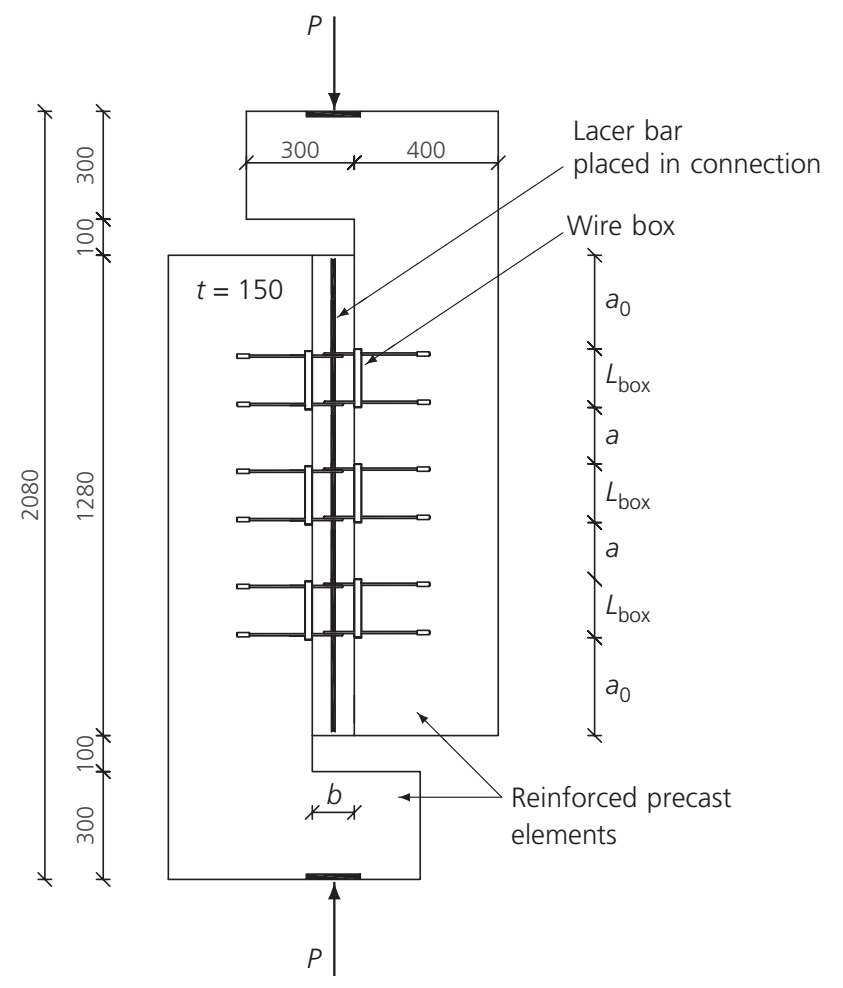

Figure 9. Specimen layout (dimensions in $\mathrm{mm}$ ) was ascertained to be $30.5 \mathrm{kN}$ on average, which corresponds to a mean tensile strength of $f_{\mathrm{uw}}=1078 \mathrm{MPa}$.

In some of the tests, the wire boxes were placed close to the end of the connection at positions where the lock bar was not fully anchored. Since the theoretical solutions are based on the assumption of fully anchored lock bars (i.e. the yield stress of the lock bar is used in the developed models), a reduced yield stress has to be used if the lock bar crosses yield lines or wire loops within its development length. According to Eurocode 2 (Danish Standards, 2005), the anchorage length required to develop yielding in a straight bar can be estimated as

$$
\text { 23. } l_{\mathrm{b}}=\frac{\phi_{\mathrm{L}}}{4} \frac{f_{\mathrm{yL}}}{2 \cdot 25 \times 0 \cdot 3\left(f_{\mathrm{c}}-8\right)^{2 / 3}}
$$

In the calculations, if the distance, $l_{\mathrm{a}}$, from the end of the lock bar to the position of a diagonal yield line or a pair of overlapping wire loops is smaller than $l_{\mathrm{b}}$, then the yield stress $f_{\mathrm{yL}}$ of the lock bar is reduced by a factor of

$$
\text { 24. } \quad R_{\mathrm{y}, \mathrm{L}}=\frac{l_{\mathrm{a}}}{l_{\mathrm{b}}}
$$

Note however, that the length of connections in practice typically corresponds to at least the height of one storey of a building and the assumption of fully anchored lock bars would be reasonable.

Figure 10 shows a comparison of the calculated and tested shear capacities. In the figure, symbols that are not filled correspond to tests where the mechanism with diagonal yield lines was critical according to the calculations. In addition, the circular symbols denote tests with single-wire boxes (i.e. $n_{\text {wire }}=1$ ) whereas square symbols denote tests with double-wire boxes 
Table 1. Geometry and material properties of tests of wire loop connections

\begin{tabular}{|c|c|c|c|c|c|c|c|c|c|c|c|c|}
\hline Test ID & $n_{\text {box }}$ & $f_{\mathrm{c}}: \mathrm{MPa}$ & b: $\mathrm{mm}$ & a: $\mathbf{m m}$ & $a_{0, a}: m m$ & $a_{0, b}: m m$ & D: $\mathrm{mm}$ & $\phi_{\mathrm{L}}: \mathrm{mm}$ & $f_{\mathrm{yL}}: \mathrm{mm}$ & $n_{\text {cycle }}$ & $P_{\text {u,test: }}$ kN & $P_{\mathrm{u}, \mathrm{cal}}: \mathrm{kN}$ \\
\hline \multicolumn{13}{|c|}{ Tests with double-wire boxes $\left(n_{\text {wire }}=2\right)$ and dimensions $b_{\text {box }} \times L_{\text {box }}=35 \times 180 \mathrm{~mm}$} \\
\hline 1 & 3 & $24 \cdot 8$ & 80 & 120 & 250 & 250 & 38 & 12 & 617 & 0 & $174 \cdot 9$ & $142 \cdot 0$ \\
\hline 2 & 3 & $24 \cdot 8$ & 80 & 120 & 250 & 250 & 38 & 12 & 617 & 3 & $160 \cdot 8$ & $142 \cdot 0$ \\
\hline 3 & 3 & $24 \cdot 8$ & 80 & 120 & 250 & 250 & 38 & 12 & 617 & 3 & $146 \cdot 7$ & $142 \cdot 0$ \\
\hline 7 & 3 & $24 \cdot 8$ & 100 & 120 & 250 & 250 & 44 & 12 & 617 & 0 & $177 \cdot 6$ & $147 \cdot 4$ \\
\hline 8 & 3 & 24.8 & 100 & 120 & 250 & 250 & 44 & 12 & 617 & 3 & $176 \cdot 4$ & $147 \cdot 4$ \\
\hline 9 & 3 & $24 \cdot 8$ & 100 & 120 & 250 & 250 & 44 & 12 & 617 & 50 & $185 \cdot 7$ & $147 \cdot 4$ \\
\hline \multicolumn{13}{|c|}{ Tests with double-wire boxes $\left(n_{\text {wire }}=2\right)$ and dimensions $b_{\text {box }} \times L_{\text {box }}=80 \times 220 \mathrm{~mm}$} \\
\hline 13 & 3 & $24 \cdot 8$ & 80 & 120 & 190 & 190 & 45 & 12 & 617 & 0 & $236 \cdot 7$ & $229 \cdot 5$ \\
\hline 14 & 3 & $24 \cdot 8$ & 80 & 120 & 190 & 190 & 45 & 12 & 617 & 3 & $213 \cdot 6$ & $229 \cdot 5$ \\
\hline 15 & 3 & $24 \cdot 8$ & 80 & 120 & 190 & 190 & 45 & 12 & 617 & 3 & $194 \cdot 4$ & $229 \cdot 5$ \\
\hline 16 & 3 & $24 \cdot 8$ & 120 & 120 & 190 & 190 & 65 & 12 & 617 & 0 & $246 \cdot 6$ & $242 \cdot 8$ \\
\hline 18 & 3 & $24 \cdot 8$ & 120 & 120 & 190 & 190 & 65 & 12 & 617 & 50 & 221.4 & $242 \cdot 8$ \\
\hline
\end{tabular}

Table 2. Geometry and material properties of tests from the literature

\begin{tabular}{|c|c|c|c|c|c|c|c|c|c|c|c|}
\hline Test ID & $n_{\text {box }}$ & $f_{\mathrm{c}}: \mathrm{MPa}$ & $b: \mathrm{mm}$ & a: $\mathrm{mm}$ & $a_{0, a}: m m$ & $a_{0, b}: m m$ & D: $\mathrm{mm}$ & $\phi_{\mathrm{L}}: \mathrm{mm}$ & $f_{\mathrm{yL}}: \mathrm{mm}$ & $P_{\mathrm{u}, \text { test }}: \mathrm{kN}$ & $P_{\mathrm{u}, \mathrm{cal}}: \mathrm{kN}$ \\
\hline \multicolumn{12}{|c|}{ Andersen and Poulsen (2002) } \\
\hline \multicolumn{12}{|c|}{ Tests with single-wire boxes $\left(n_{\text {wire }}=1\right)$ with $b_{\text {box }} \times L_{\text {box }}=35 \times 160 \mathrm{~mm}$} \\
\hline $1 \mathrm{~A}$ & 2 & 40 & 100 & 160 & 560 & 400 & 54 & 12 & 641 & $103 \cdot 5$ & $91 \cdot 0$ \\
\hline $1 \mathrm{~B}$ & 2 & 40 & 100 & 160 & 560 & 400 & 54 & 12 & 641 & $113 \cdot 2$ & $91 \cdot 0$ \\
\hline $2 \mathrm{~A}$ & 3 & 36 & 100 & 160 & 400 & 240 & 54 & 12 & 641 & 158.9 & $127 \cdot 7$ \\
\hline $2 B$ & 3 & 36 & 100 & 160 & 400 & 240 & 54 & 12 & 641 & $154 \cdot 0$ & $127 \cdot 7$ \\
\hline $3 \mathrm{~A}$ & 4 & 36 & 100 & 160 & 240 & 80 & 54 & 12 & 641 & 181.9 & $166 \cdot 9$ \\
\hline $3 B$ & 4 & 36 & 100 & 160 & 240 & 80 & 54 & 12 & 641 & $202 \cdot 0$ & $166 \cdot 9$ \\
\hline $4 \mathrm{~A}$ & 2 & 36 & 100 & 160 & 560 & 400 & 54 & 12 & 641 & $115 \cdot 4$ & $85 \cdot 1$ \\
\hline $4 B$ & 2 & 36 & 100 & 160 & 560 & 400 & 54 & 12 & 641 & $107 \cdot 4$ & $85 \cdot 1$ \\
\hline $7 \mathrm{~A}$ & 2 & 36 & 100 & 800 & 240 & 80 & 54 & 12 & 641 & $77 \cdot 0$ & $81 \cdot 7$ \\
\hline $7 \mathrm{~B}$ & 2 & 36 & 100 & 800 & 240 & 80 & 54 & 12 & 641 & $69 \cdot 5$ & $81 \cdot 7$ \\
\hline \multicolumn{12}{|c|}{ Frederiksen and Madsen (2011) } \\
\hline \multicolumn{12}{|c|}{ Tests with single-wire boxes $\left(n_{\text {wire }}=1\right)$ with $b_{\text {box }} \times L_{\text {box }}=35 \times 160 \mathrm{~mm}$} \\
\hline $1 \mathrm{~A}$ & 2 & $26 \cdot 7$ & 80 & 160 & 400 & 400 & 38 & 12 & 617 & $54 \cdot 8$ & 69.5 \\
\hline 1B & 2 & $26 \cdot 7$ & 80 & 160 & 400 & 400 & 38 & 12 & 617 & $59 \cdot 8$ & $69 \cdot 5$ \\
\hline $1 \mathrm{C}$ & 2 & $26 \cdot 7$ & 80 & 160 & 400 & 400 & 38 & 12 & 617 & $56 \cdot 6$ & 69.5 \\
\hline $2 \mathrm{~A}$ & 4 & $26 \cdot 2$ & 80 & 160 & 80 & 80 & 38 & 12 & 617 & $128 \cdot 1$ & $127 \cdot 0$ \\
\hline $2 B$ & 4 & $26 \cdot 2$ & 80 & 160 & 80 & 80 & 38 & 12 & 617 & $108 \cdot 8$ & $127 \cdot 0$ \\
\hline $2 C$ & 4 & $26 \cdot 2$ & 80 & 160 & 80 & 80 & 38 & 12 & 617 & $119 \cdot 3$ & $127 \cdot 0$ \\
\hline $2 \cdot 1 \mathrm{~A}$ & 4 & $18 \cdot 3$ & 80 & 160 & 80 & 80 & 38 & 12 & 617 & $101 \cdot 9$ & $97 \cdot 4$ \\
\hline $12 \mathrm{~A}$ & 4 & $26 \cdot 7$ & 80 & 160 & 80 & 80 & 38 & 16 & 618 & $111 \cdot 1$ & $136 \cdot 9$ \\
\hline $12 \mathrm{~B}$ & 4 & $26 \cdot 7$ & 80 & 160 & 80 & 80 & 38 & 16 & 618 & $116 \cdot 1$ & $136 \cdot 9$ \\
\hline $12 \mathrm{C}$ & 4 & $26 \cdot 7$ & 80 & 160 & 80 & 80 & 38 & 16 & 618 & $110 \cdot 1$ & $136 \cdot 9$ \\
\hline $13 \mathrm{~A}$ & 4 & $23 \cdot 5$ & 80 & 160 & 80 & 80 & 38 & 0 & - & $54 \cdot 7$ & $75 \cdot 2$ \\
\hline $13 B$ & 4 & $23 \cdot 5$ & 80 & 160 & 80 & 80 & 38 & 0 & - & 67.9 & $75 \cdot 2$ \\
\hline $13 C$ & 4 & $23 \cdot 5$ & 80 & 160 & 80 & 80 & 38 & 0 & - & 68.0 & $75 \cdot 2$ \\
\hline \multicolumn{12}{|c|}{ Tests with double-wire boxes $\left(n_{\text {wire }}=2\right)$ with $b_{\text {box }} \times L_{\text {box }}=80 \times 220 \mathrm{~mm}$} \\
\hline 9A & 2 & $26 \cdot 7$ & 100 & 120 & 360 & 360 & 55 & 12 & 617 & $130 \cdot 3$ & $160 \cdot 1$ \\
\hline 9B & 2 & $26 \cdot 7$ & 100 & 120 & 360 & 360 & 55 & 12 & 617 & $148 \cdot 2$ & $160 \cdot 1$ \\
\hline 9C & 2 & $26 \cdot 7$ & 100 & 120 & 360 & 360 & 55 & 12 & 617 & $123 \cdot 2$ & $160 \cdot 1$ \\
\hline \multicolumn{12}{|c|}{ Tests with double-wire boxes $\left(n_{\text {wire }}=2\right)$ with $b_{\text {box }} \times L_{\text {box }}=35 \times 180 \mathrm{~mm}$} \\
\hline $10 \mathrm{~A}$ & 2 & $26 \cdot 7$ & 80 & 120 & 400 & 400 & 38 & 12 & 617 & $122 \cdot 1$ & $104 \cdot 1$ \\
\hline $10 \mathrm{~B}$ & 2 & $26 \cdot 7$ & 80 & 120 & 400 & 400 & 38 & 12 & 617 & $112 \cdot 9$ & $104 \cdot 1$ \\
\hline $10 \mathrm{C}$ & 2 & $26 \cdot 7$ & 80 & 120 & 400 & 400 & 38 & 12 & 617 & 114.4 & $104 \cdot 1$ \\
\hline
\end{tabular}




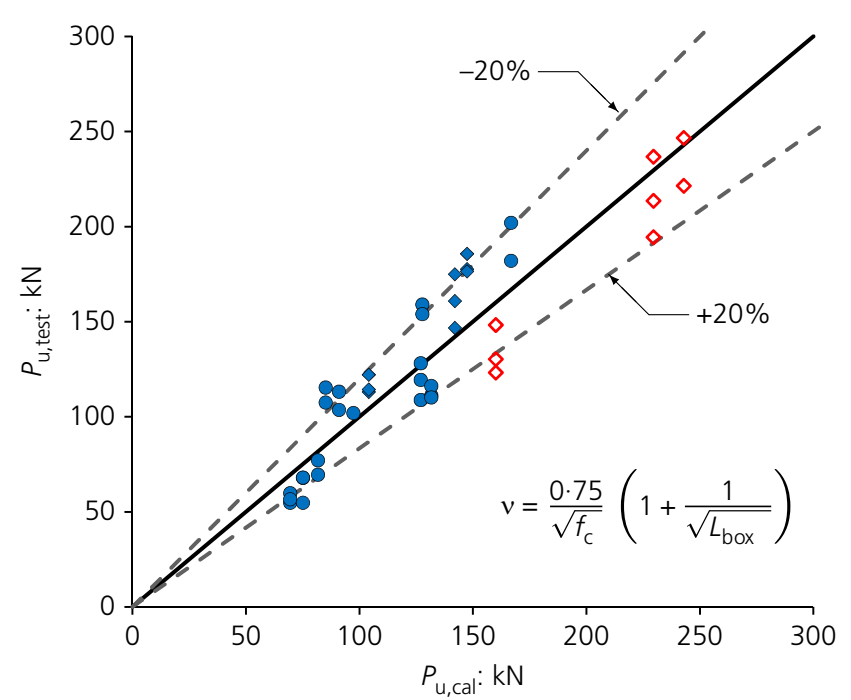

Figure 10. Comparison of calculated shear capacity $\left(P_{\mathrm{u}, \mathrm{cal}}\right)$ and tested shear capacity $\left(P_{\mathrm{u}, \text { test }}\right)$

$\left(n_{\text {wire }}=2\right)$. The calculations were performed by adopting the effectiveness factor given in Equation 22. A mean value of 1.02 was obtained for the test to model ratio for all the tests listed in Tables 1 and 2. The corresponding standard deviation amounted to $0 \cdot 17$ (see Joergensen, 2014).

The test results of specimens that, according to calculations, should fail without the development of diagonal yield lines are collected in Figure 11 (i.e. tests that are predicted by Equation 14). In this plot, the dependency of the transverse reinforcement degree, $\Phi_{\mathrm{T}}$, on the shear strength, $P_{\mathrm{u}}$, is clearly seen.

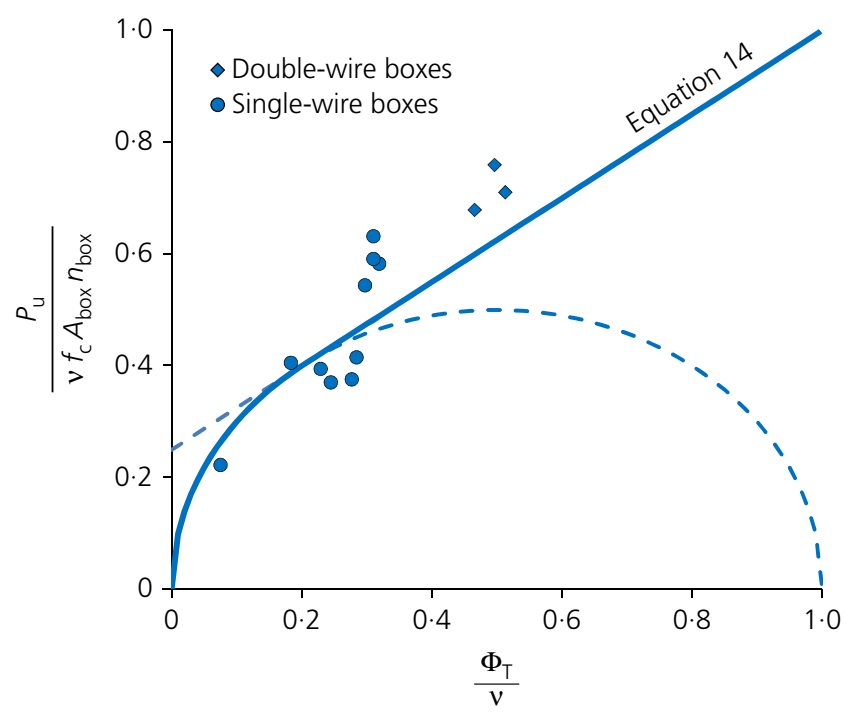

Figure 11. Comparison of model with test results for specimens predicted to fail without development of diagonal yield lines
The size of the lock bar is an important design parameter in practice. When calculating the shear strength from the mechanism without diagonal yield lines, an upper limit for the effect of the lock bar is found. In other words, when the magnitude of $A_{\mathrm{sL}} f_{\mathrm{yL}}$ (and thus the magnitude of $\sigma_{\mathrm{con}}$ ) reaches a certain level, $F_{\text {wire }}$ according to Equation 10 can no longer be increased. This means that $F_{\text {wire }}=1 / 2 A_{\mathrm{c}} f_{\mathrm{cc}}$. Figure 12 compares the calculated and tested shear strengths versus the mechanical ratio of lock bar reinforcement, $\Phi_{\mathrm{L}}$. The two series of tests are identical with the exception of the lock bar diameter (the difference in mortar strength was insignificant). According to calculations, $F_{\text {wire }}=1 / 2 A_{\mathrm{c}} f_{\mathrm{cc}}$ for both series and thus both series have theoretically the same shear capacity. This result seems to be confirmed by the tests, which showed no increase in shear capacity when the lock bar diameter was increased from $12 \mathrm{~mm}$ to $16 \mathrm{~mm}$.

\section{Conclusions}

Experimentally observed failure mechanisms were used as inspiration to develop upper bound plastic solutions for the inplane shear capacity of wire loop connections. Two different failure modes were treated. In the first mode (failure mode 1), yield lines only develop along the joint surfaces and cut through the opening areas of the mortar-filled wire boxes. In the second mode (failure mode 2), diagonal yield lines also develop, running across the connection from one edge of a wire box to the opposite edge of the adjacent box.

In order to apply the presented plastic solutions, it is required that rupture does not take place in the wire ropes due to their brittle behaviour in uniaxial tension. In this context, a simple model for the tensile capacity of pairs of overlapping wire loops was developed for the case where crushing of the confined mortar is governing. The model is based on a combination of the failure criteria for concrete and for cement paste

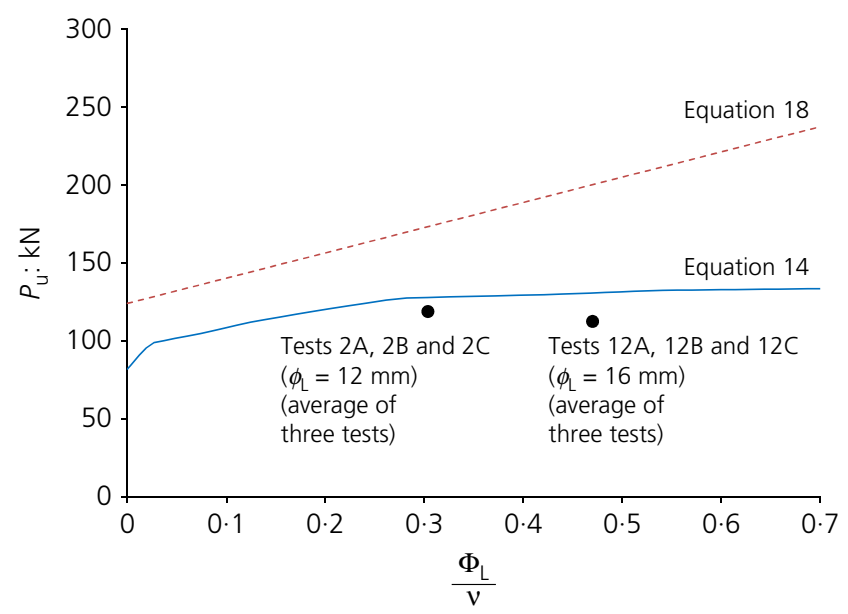

Figure 12. Comparison of model with test results for specimens where only the lock bar diameter is changed 
and enables the designer to choose a design where rupture of wire ropes can be avoided. The results of the tensile capacity model were used in calculations of the internal plastic work associated with the shear failure. The solution for the tensile capacity of overlapping wire loops can only be used for wire loops from two opposing wire boxes (i.e. the model presented can only be used for wall elements placed in the same plane).

The number of shear tests of wire rope connections available to the public is very limited, especially tests with double-wire boxes. An experimental programme comprising 11 shear tests of connections designed with double-wire boxes was presented in this paper.

The shear strength model predicts failure mode 1 when the mechanical degree of transverse reinforcement (i.e. wire loops) is low. For a higher degree of transverse reinforcement, failure mode 2 is critical. The model was compared with the test results summarised in Tables 1 and 2. It was found that the model captures some important tendencies fairly well and provides satisfactory overall agreement.

\section{Acknowledgements}

The authors would like to acknowledge support from the Danish Federation of Precast Concrete Elements in the donation of test specimens. The authors would also like to acknowledge financial support for the first author's $\mathrm{PhD}$ study from the Danish Research and Innovation Council and the Danish Federation of Precast Concrete Elements.

\section{REFERENCES}

Andersen HB and Poulsen DG (2002) Liner i prafabrikerede betonelementer. Master's thesis, Department of Civil Engineering, Technical University of Denmark, Lyngby, Denmark (in Danish).
Bachmann H and Steinle A (2011) Precast Concrete Structures, 1st edn. Ernst and Sohn, Berlin, Germany.

Dahl KKB (1992) A Failure Criterion for Normal and High Strength Concrete. Department of Structural Engineering, Technical University of Denmark, Lyngby, Denmark, Technical report R-286.

Danish Standards (2005) DS/EN 1992-1-1: Eurocode 2: Design of concrete structures - part 1-1: general rules for buildings, 2 nd edn. Danish Standards, Nordhavn, Denmark.

Frederiksen MS and Madsen K (2011) Elementsamlinger med wirebokse - eksperimentel undersogelse af forskydningsstyrker og deformationsegenskaber. Master's thesis, Architectural Engineering, Aarhus School of Engineering, Aarhus, Denmark (in Danish).

Hagsten LG (2013) Element Connection with Pfeifer Wireboxes. Aarhus University School of Engineering, Aarhus, Denmark, Technical report.

Hansen TC (1994) Triaxial Tests with Concrete and Cement Paste. Department of Structural Engineering, Technical University of Denmark, Lyngby, Denmark, Technical report R-319.

Hansen K, Kavyrchine M, Melborn G et al. (1976) Sbi-Report 97: Keyed Shear Joints. Danish Building Research, Teknisk Forlag, Copenhagen, Denmark.

Jensen BC (1976) Nogle plasticitetsteoretiske beregninger af beton og jernbeton. PhD thesis, Institute of Building Design, Technical University of Denmark, Lyngby, Denmark (in Danish).

Joergensen HB (2014) Strength of Loop Connections between Precast Concrete Element - Part 1: U-bar Connections Loaded in Combined Tension and Bending - Part 2: Wire Loop Connections Loaded in Shear. PhD thesis, University of Southern Denmark, Odense, Denmark.

Kintscher MR (2007) The VS® system - a success story achieved through consistent further development. BFT International 73(8): 26-39.

Mattock AH and Hawkins NM (1972) Shear transfer in reinforced concrete - recent research. PCI Journal 17(2): 55-75.

Nielsen MP and Hoang LC (2011) Limit Analysis and Concrete Plasticity, 3rd edn. CRC Press, Boca Raton, FL, Unites States.

Zhang JP (1994) Strength of Cracked Concrete, Part 1 - Shear Strength of Conventional Reinforced Concrete Beams, Deep Beams, Corbels and Prestressed Reinforced Concrete Beams Without Shear Reinforcement. PhD thesis, Department of Structural Engineering and Materials, Technical University of Denmark, Lyngby, Denmark, Report R-311.

\section{How can you contribute?}

To discuss this paper, please email up to 500 words to the editor at journals@ice.org.uk. Your contribution will be forwarded to the author(s) for a reply and, if considered appropriate by the editorial board, it will be published as discussion in a future issue of the journal.

Proceedings journals rely entirely on contributions from the civil engineering profession (and allied disciplines). Information about how to submit your paper online is available at www.icevirtuallibrary.com/page/authors, where you will also find detailed author guidelines. 